Wolfgang Spobn

\title{
A PRIORI REASONS: TWO DIFFICULT NOTIONS AND AN EVEN MORE DIFFICULT CONNECTION
}

\section{Discontent}

I am not very satisfied by the familiar accounts of our two key notions and their relation. There is no point here in extensive critical discussions. Let us look just at two prominent examples.

When one wants to know what knowledge is, one needs to know what true justified belief is. Part of the issue thus is when to call a belief justified. This is hotly debated, producing more smoke than fire. However, all parties roughly agree on the following pneumatic or rather hydrodynamic picture of justification: There are all the propositions, possible objects of belief, each being represented by a kind of bulb. The propositions entertain justificatory relations, represented by channels or pipes between the bulbs, the width of the pipes corresponding to the strength of the justificatory relations. So far, we have an empty justificatory network. Now, however, we pour some viscous fluid into the network, called warrant, which diffuses through the pipes. Most of the bulbs remain empty, i.e., unbelieved, but many bulbs get filled by warrant, i.e. believed, and the amount of fluid they contain corresponds to their degree of justification.

This is a very intuitive picture and thus widely shared. ${ }^{1}$ Disagreement emerges about the issue where that fluid comes from. Foundationalists say that it is produced in special basic bulbs, be they a priori propositions, sense-data, or whatever. Coherentists say that it is produced by the network itself, in the pipes or by a special kind of clustering. Externalists say that it is not produced in the belief network at all, but by facts extraneous to the network. Contextualists say that, wherever warrant is produced, how much of it diffuses through the network depends on the context in which the network is situated. And so on.

These are important divergences. What irritates me more, though, is the apparent uncritical acceptance of the hydrodynamic picture of justification. It is just a

\footnotetext{
${ }^{1}$ Cf., e. g., Bonjour (1985, sect. 2.1), Audi (2003, ch. 7, in particular pp. 192ff.) and Ernst (2007, ch. 6).
} 
picture, desperately in need, but totally void of theoretical explications. Those using it apparently do not see the need, and those potentially having the theoretical means apparently have no hope. How precisely are we to understand the justificatory relations between propositions or beliefs? And how precisely does a single belief acquire a degree of justifiedness through these relations? We should not continue on the above divergences without good answers to such questions.

Or look at the following attempts at apriority: If knowledge is justified true belief, then a priori knowledge is true belief justified in an a priori manner. This sounds plausible, and it may indeed be a promising theoretical move ${ }^{2}$ to consider justification as the basic bearer of apriority. However, what are a priori justificatory relations? If the only well-elaborated example is given by deductive relations, the relations? If the of wellorm. And presumably those a priori justificatory relations must take their start at some a priori beliefs? Thus, we sink into the obscurities of the hydrodynamic picture, if not in vicious circles. Again, the hope for theoretical progress seems thwarted.

If we are to make progress here, we need a theoretical perspective, I believe, that provides clear access to each of the two notions, and indeed to both at once, if we are to gain insight into their relations. In this paper I want to propose such a perspective and to explain the access it provides. The perspective is familiar; it is the dynamical perspective of the theory of rational belief change. The details will be explained in the next two sections on reasons and on apriority, the substance of this paper. However, one point is clear from the outset, namely that this dynamical perspective is a theoretically powerful one, since there are well founded, thoroughly elaborated theories of rational belief change in the consequences of which we can trust. That is to say, whenever we reach results that may be prima facie dubious, the weight of intuitions stands against the weight of theory; but if the theory is powerful and intuitively well founded in turn, it tends to override intuition. The theories of rational belief change are such theories, and therefore we are well advised to listen to their explicatory power.

Before moving to the main sections, I have to make a terminological point. It is a rich and amusing topic how philosophy is influenced by the language in which it is expressed. Concerning the issues at hand, I feel English is less well prepared than German. So far, I have used the terms "justification" and "warrant", in German "Rechtfertigung" and "Gewähr«. However, I do not like the moral undertones of "justification «; in epistemological matters rendering account towards others is important, but secondary. And I do not like the legal undertones of "warrant"; in empirical matters there are no guarantees, and nature does what it does and is not liable to recourse. What is really at issue is the German triad »Grund «, is not liable to recourse. What is really at issue is the German triad »Grund «,
»begründen«, and "Begründung«. The first is well translated by »reason« in the

${ }^{2}$ Explicitly taken, e.g., by Kitcher (1980) (see also Kitcher 2000) and Burge (2001). sense of »being a reason for «; so, there is at least one translational bridge. The second, however, is badly translated by »to reason «; it rather means »to give reasons for ". Likewise, the third is badly translated by »reasoning «. Thus, I am in a terminological predicament. Either, I have to use clumsy English by talking of sthe reason relation" and suchlike, or I have to use terms that are slightly incorrect in my view. I shall do both - and emphasize at the outset that I shall be talking only about the German triad and nothing else. »Apriority « by contrast, is a philosophical term of art in English as in German and thus precarious as such, but to the same degree in both languages.

\section{REASONS}

I have announced to consider our key notions within the perspective of rational belief change. How do reasons relate to this perspective? The relation is perfectly straightforward. Rationally - and in philosophical epistemology we only consider what is rational -, reasons and nothing else drive belief change or the doxastic dynamics; any doxastic change has to have a reason or is not rational. The present doxastic state is formed by the reasons already received; and it is changed only by receiving new reasons. Everybody subscribes to this.

The interesting point is the direction of these assertions. The dominant picture, I think, is that we therefore need a good account of what reasons are in order to derive a theory of rational belief change. However, the long history of inductive skepticism, most prominently pushed by Hume, teaches us that this means overburdening the notion of a reason. There is no, as it were, objective notion of a reason guiding rational belief change. There is the saying: the one's modus ponens is the other's modus tollens. And similarly: the one's reason is the other's counter-reason - see Goodman's (1955) new riddle of induction.

Hence - this is a profound point that can be only insufficiently argued in such a short paper - the direction should be reversed: We have no independent notion of a reason; rather, reasons are whatever drives rational belief change. ${ }^{3}$ Given the well elaborated theories of doxastic change, which notion of a reason is thereby entailed?

All these theories - there are in fact only two main candidates: Bayesianism or probability theory and ranking theory (cf. Spohn 1983, sect. 5.3, and 1988) or equivalent theories such as possibility theory (cf. Dubois, Prade 1988) - utilize the notion of conditionalization: Each doxastic state assigns degrees of belief to

${ }^{3}$ Haas (2005) is the only one, as far as I know, to have elaborated the connection between reasons
and belief change within the realm of su-called belief revision theory - cf., e. g., Gärdenfors (1988). However, he has shied away from this radical reversal of the connection. 
all propositions under consideration; this entails conditional degrees of belief for each proposition and each condition; and then the posterior degree of belief of a proposition is its prior degree given the condition that is received as evidence. This is the simplest model (and we do not have to look at more sophisticated models like generalized conditionalization as invented by Jeffrey 1965 , ch. 11).

Hence, being a reason simply consists in relevance, or rather in positive relevance: $A$ is a reason for $B$ if and only if $B$ is more strongly believed given $A$ than without $A$. Correspondingly, $A$ is a reason against $B$ if and only if the degree of belief in $B$ is lowered by $A$. Thus, learning $A$ changes the (degree of belief in precisely those propositions for or against which $A$ is a reason. This is not only the theoretically required, but also an intuitively most plausible explication. ${ }^{4}$ At the same time it makes clear that only theories providing a notion of conditional degrees of belief are able to implement this explication; this is why probability and ranking theory are the main candidates for adequately capturing reasons. ${ }^{5}$

Clearly, this explication is relative to a given doxastic state; relative to another doxastic state, the extension of the reason relation may be quite different. This is the price to be paid for inductive skepticism; the fight for constraining relativity and establishing more objectivity cannot start by presupposing a more objective notion of good reasons. Also, this relativity does not make this fight a forlorn case, just as it does not render entirely empty the assertion that reasons drive belief change. We are talking never about factual dynamics, but always about rational doxastic change. What »rational « is to mean here is not fixed in advance, but always open to discussion. The crucial and exciting point is how far this discussion carries us. Of course, not very far in this paper. Let me just point out a number of simple consequences of our dynamic explication of reasons.

One consequence is that the reason relation may behave in an unexpected way. For instance, two reasons may conjoin to form a counter-reason. Or there is the foundationalist conception that justification stepwise extends from a somehow unproblematic base; this presupposes, however, that justification is transitive, a presupposition that is not met by our explication. ${ }^{6}$ Instead, the reason relation is symmetric; whenever $A$ is a reason for $B, B$ is a reason for $A$; support is always mutual. Such unexpected behavior does not point to inadequacies in our modeling of the reason relation. On the contrary, one must closely study these models in order to learn about the complexities of that relation.

\footnotetext{
${ }^{4}$ There are various ideas for explicating the notion of a reason. In Spohn (2001) I have comparatively discussed these ideas and argued that the notion of a reason being positively relevant is the basic one. 5 For an excellent survey over the existing theories of degrees of belief see Halpern (2003) and Huber,
Fons Schmidt-Petri (forthcoming).
}

${ }^{6}$ See also Salmon (1975), a nice paper pointing to such peculiarities within the probabilistic frame.
It rather points to the fact that our intuitions are shaped by an insufficient model, namely the model of deductive reasons. One may say that $A$ is a deductive reason for $B$ just in case $A$ logically entails $B$. Deductive reasons do not show the behavior exemplified above; they are, e.g., transitive and not symmetric. However, it is important to realize that our intuitive notion of a reason is much wider and that it must not be thought of in analogy to the deductive model. This point is well captured by the above explication which essentially embraces the deductive notion. To be precise: if $A$ is a deductive reason for $B$, then $A$ is a reason for $B$ (in the sense of positive relevance), provided neither $A$ nor $B$ is logically true or logically false.

The definition of deductive reasons did not mention any relativity to doxastic states; it has none. This is their great advantage; deductive reasons are so across all doxastic states. This observation will become important in the next section. ${ }^{7}$ However, this objectivity is deceptive; it does not carry over to the more general notion of positive relevance.

The relation just noted between deductive reasons and reasons in general shows another consequence, namely that logical truths and logical falsities have no reasons and are no reasons (and we shall see in the next section that we may here replace $» \operatorname{logical}$ « by »a priori«). This is not surprising from our dynamical perspective. Logical truths and falsehoods are not subject to any doxastic dynamics and can hence not enter into reason relations. I admit that this consequence is also due to the fact that the dynamical models I am referring to, probability and ranking theory, only deal with the dynamics of empirical belief and are silent on the formation of logical and mathematical belief. This, however, is not their special failure; there simply are no good theories treating these kinds of belief. All this indicates how precarious an idea it is to base the notion of a priori beliefs on that of a priori justification.

Is there a way to save the hydrodynamic picture of justification within the precise models of rational belief change? Yes, perhaps. Reasons can be stronger or weaker; this corresponds to the width of the pipes, the strength of the justificatory relations. The problem is to get from the binary justificatory relations to the unary degrees of justifiedness. I do not know of any serious account of this step. Perhaps, though, ranking theory is suited for modeling it. Usually, ranking theory is explained in terms of negative ranks, i.e., degrees of disbelief. Of course, it can be equally well stated in terms of positive ranks, i. e., degrees of belief. These degrees of belief can as well be understood as degrees of justifiedness. In particular, positive rank 0 expresses rational non-belief, and this precisely corresponds to nonjustifiedness, i.e., to an empty bulb. Thus, the rules of distributing positive ranks could mirror the hydrodynamics of that fluid I called warrant, and we could then

\footnotetext{
${ }^{7}$ Gärdenfors (1988, ch. 6) made the interesting and successful attcmpt to base logic on that observation.
} 
confirm that this fluid more easily flows through the thicker pipes. (Subjective probabilities seem less suited for explicating the hydrodynamic picture, because there is no determinate probability that could be said to represent a bulb being empty).

Still, there remains the issue where the warrant fluid comes from. I mentioned that this is a point of wide disagreement. As often, the disagreement is so persistent, I think, because each side is partially correct. In fact, I believe that quite a traditional picture applies which is easily misrepresented, though, and thus seems objectionable:

According to this traditional picture warrant is generated by perceptions or impressions or, philosophically togged up, by phenomenally conscious states of mind; insofar, foundationalists are right. This is so because such states of consciousness are peculiar hybrids, as I have more extensively argued in Spohn (2005); they are beliefs and non-beliefs at the same time! 'Take an example: I sit at my desk and have a visual impression; it looks thus to me. Although I can describe a lot of details of my impression - whether or not they are veridical -, it is important that the "thus " cannot be substituted by any description; in a certain harmless sense my impression is ineffable. There is a bit of truth in Russell's doctrine of logically proper names. Now, this impression is conscious to me, and if I am right in my (2005), this means that I ipso facto believe that it looks thus to me. (As soon as you replace »thus « by, say, »as if $p \ll, » p$ « being some linguistic description, look and belief may fall apart.) In this special case and only in this special case the belief state and its object, the non-doxastic sensory state, are one and the same. Hence, there is a truth guarantee of the strongest kind for this belief, namely identity instead of correspondence; that is the source of warrant. For the same reason this belief is maximally certain.

So, foundationalists are right again; there are even basic beliefs. However, externalists are also right; warrant originates from facts outside the doxastic circle, though not far outside. The strange identity of conscious states compels us to speak so paradoxically.

However, foundationalists are also wrong about the justificatory role of those basic perceptual beliefs. First of all, they are momentary; after a while I only believe that it looked thus to me, and thus the basic belief has turned into a more or less uncertain recollection. Thus, with their ineffability and their transitoriness these basic beliefs are much like the "Konstatierungen « described by Schlick (1934). Moreover, these basic beliefs do not enter the circle of reasons because of their maximal certainty, as do beliefs in logical truths. Rather, they generate less than maximally certain beliefs with the slightly different content that it looks to me as if $p$. Only the latter belong to the playground of reasons as described above. They can be confirmed or even turn out false; they defeasibly entail that $p$; or I may believe for other reasons that non- $p$, although it looks as if $p$; etc. As I have more carefully argued in Spohn (1997/98), a coherentist picture then is much more adequate than a foundationalist one. Thus runs my proposal to take a bit of truth from every side and to thereby form an almost traditional picture avoiding traditional problems.

I could not do better than speaking figuratively in the preceding paragraphs. One must never forget, though, that all this finds a precise ranking theoretic explication. It is, in particular, the theory of Bayesian nets transferred to ranking theory that allows for such a formal representation. ${ }^{8}$

All this should have given a good impression of how reasons (or justifications) may be accounted for within the dynamic perspective of belief change. In particular, it should have become clear how strong the guidance offered by this perspective is. This guidance will continue when we now apply this perspective to the notion of apriority.

\section{APRIORITY}

The dynamic perspective seems indeed ideally suited for explicating apriority. In particular, it brings an important ambiguity of the notion of apriority to the fore, which seems to be neglected under the influence of Kant and only recently observed. The traditional notion is that those propositions are believed (or known) a priori that are believed independently of any experience. This may, however, be understood in two ways. It may mean that a priori beliefs are held whatever the experience, or it may mean that a priori beliefs are held without any experience. This is a dramatic difference.

The dynamic perspective well explains the difference. The first sense is characterized by invariance under all possible sequences of experience, i.e., under all possible doxastic dynamics; and the second sense is characterized by what is initially believed, i.e., believed at the beginning of the experiential evolution of beliefs. Moreover, this difference obviously applies not only to what is believed a priori, but in fact to any feature of a doxastic state. Believing a certain proposition is one possible feature of a doxastic state. Yet there are many others. In particular we have seen that certain reason relations may be such features obtaining in some doxastic states, but not necessarily in others; this will open a quite different perspective on the topic of a priori justification. We thus arrive at the following two notions of apriority:

A feature of a doxastic state is unrevisably a priori if and only if each possible rational doxastic state has it. This entails that such a feature is preserved throughout all possible evolutions of rational doxastic states; this is why I call it unrevisable

\footnotetext{
${ }^{8}$ Cf. Hunter $(1$

but the

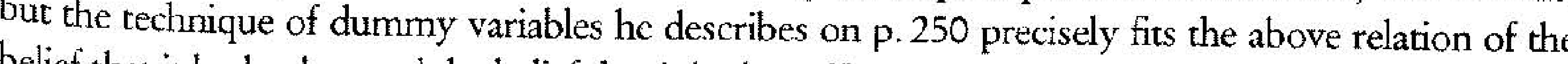
belief that it looks thus and the belief that it looks as if $p$.
} 
apriority. A feature of a doxastic state is defeasibly a priori if and only if each initia doxastic state has it, i.e., each doxastic state prior to the influence of experience. Such features are called defeasibly a priori because they may be lost under the influence of experience; I shall mention examples how this may happen. What »initial « here precisely means is apparently not very clear; we shall address this issue below.

Restricted to propositions believed, unrevisable apriority is just the traditional notion of apriority so central in particular to Kantian philosophy. It is also the notion attacked by Quine (1951) in his second criticism of what he there calls analyticity, and it is Kripke's (1972) notion of apriority in his fundamental reform of metaphysical and epistemological modalities. Defeasible apriority is, as far as I know, a more recent discovery. For instance, it is implicit, yet important in Pollock's account of defeasible reasoning (cf., e.g., Pollock 1995); and it is roughly Field's (1996) notion of weak apriority. My impression is that it is still not generally well acknowledged and accepted. In any case, we must note that the dynamic perspective provides a double extension of the topic: not only a distinction of two senses of apriority, but also an extension of the objects of apriority beyond propositions (or judgments). Let me address the two kinds of apriority in a bit more detail.

Unrevisable apriority applied to propositions is a well-treated topic that is, as far as I can see, not enriched by our dynamic perspective. There are all the well known examples: logical truths, analytic truths, mathematical truths, Cartesian truths, as one might call them, such as "I exist now", which actually form quite a big class (there is not only Descartes' cogito), color exclusion sentences, and not much more. In all these examples the source of apriority seems to lie in the concepts used; the a priori truths seem to be conceptual truths. This is not to say, however, that they are analytic truths. I adhere to Kripke's (1972) explication that analytic truths are a priori metaphysically necessary and not only a priori true, a distinction well accounted for in two-dimensional semantics.

However, when we widen our scope and consider other doxastic features than the belief in propositions, we see that there is at least one other source of unrevisable apriority, namely the structure of reasons. For, let us ask: Are there unrevisably a priori reason relations? Of course, there are. I had already mentioned the main example, deductive reasons or logical entailment. These reasons hold across all rational doxastic states. We can even slightly generalize the example to a priori entailment. Yet, the example is not so exciting. Logical truth and logical entailment and likewise a priori truth and a priori entailment are interdefinable; so, these a priori reason relations do not really carry us beyond propositional apriority.

There are, however, more unrevisable a priori reason relations, or rather: it is unrevisably a priori that there are more reason relations. This emerges from our dynamic perspective. Rational doxastic states must be capable of change, of learn- ing, and this means that they must contain non-deductive reason relations. (This is not yet to postulate specific non-deductive reason relations.) For instance, in his first big attempt at inductive logic Carnap (1950) discussed the so-called Wittgenstein function as a measure of confirmation. However, he could easily show that the Wittgenstein function is totally incapable of learning. This immediately disqualified it as an inductive method. Such a priori learnability principles about the reason structure of our doxastic states are a fruitful research area. I believe that quite powerful principles can thus be established as unrevisably a priori, strong coherence principles and even versions of the principle of causality. This is not the place to elaborate the point; in Spohn (2000) I have given a brief overview of the results I had obtained so far.

Defeasible apriority, being attended to only recently, is much less studied, although I think it is equally rich a topic. There are not so many historic precursors. One example is the old discussion about prior probabilities and the principles they should obey, for instance certain symmetry assumptions or the so-called principle of insufficient reason demanding an equal prior distribution. Such a distribution would be defeasibly a priori in our sense. It is prior to any experience with the subject matter at hand, say, a certain die; and it is defeasible since evidence may turn it unequal; the die may turn out to be unfair. Quite a different example would be what Scholz (1999) calls rules of presumption, which play an important role in hermeneutics, the context he focuses on, and which are discussed, in various disguises, since the 18 th century. ${ }^{9}$ Such prima facie rules may be found in many other areas as well, e.g. in the topic of testimony and its possibly special epistemological role (cf. Coady 1992). Still, all this does not add up to what deserves to be called systematic research. The field is still in a tentative state.

My own two prime examples of the defeasible a priori are quire different. The one is about ostensive definitions and the so-called paradigm case argument, which was hotly debated in the fifties (cf. Watkins 1957/58 and the other papers collected in that Analysis volume). A term or a concept is ostensively defined - and that means: not defined at all by all standards of the theory of definitions if it is learned by (pointing to) paradigms. And the paradigm case argument then claimed that it is analytic that the paradigms fall under the ostensively defined concept. It is quite obvious how problematic this claim is. For instance, for all of us (certain parts of) the surface of the earth served as a paradigm of flatness; but it is simply false, and a fortiori not analytic, that the surface of the earth is flat.

I think that analyticity, which somehow was the only category in the focus of that time, was the wrong category; defeasible apriority would have been the right one. It is defeasibly a priori that the paradigms fall under the concept ostensively introduced; they belong to the origin of the concept. Still, it may turn out later on

\footnotetext{
${ }^{9}$ See also Scholz, this volume.
} 
that some of the paradigms were bad ones - or even all: "Witch" was certainly at first ostensively learned in the Middle Ages; certain red-haired women were witch paradigms. Then, however, it was learned that it is essential for witches to be possessed by the devil. Much later, people became convinced that there is no devil and hence concluded that there can be no witches. Thus, "there are witches" is defeasibly a priori, no more and no less.

This is in fact an ironic commentary on Quine $(1969$, p. 86$)$, who rhetorically asked how to distinguish analytic truths from other concomitant, but clearly synthetic information like "there are black dogs ", thus concluding that analyticity is a hopeless notion. Again, analyticity is the wrong category. I am not sure about black dogs, but "there are dogs« is indeed not analytic, though a priori, viz. defeasibly a priori.

My other prime example is much more important, being an instance of a defeasibly a priori reason relation. It is about dispositions. These have always been a problem in philosophy. Locke felt that secondary and tertiary qualities, as he called them, are special. The logical positivists despaired of defining them and concluded that they are only partially characterizable by so-called reduction sentences that are analytically true. However, Carnap (1956) observed that these reduction sentences need to be further qualified by a ceteris paribus clause, and since then the case was considered hopeless (unless one draws upon counterfactual conditionals that are in no way clearer).

There is no place here for the fuller story (told in Spohn 1997). However, even without much argument it is immediately plausible that the allegedly analytic reduction sentences should be replaced by the following assertion: Given the relevant test situation, the presence of the disposition is a reason (in our sense) for expecting the characteristic manifestation, and vice versa. And, this is crucial, this assertion is defeasibly a priori!

Therein hide two points. First, the assertion need not always be true. Sometimes, the disposition does not manifest itself in the relevant test situation, and sometimes an object shows the characteristic behavior without having the disposition; this is why Carnap introduced the ceteris paribus clause. This may even be known to us; and this is why the asserted reason relation is defeasible. Still, that reason relation is a priori. It belongs to the dispositional concept, and one acquires it simply by acquiring the concept; no further evidence is needed for establishing the connection (as it is, e.g., for learning that smoke is a reason for assuming fire and vice versa). So, again, the source of apriority is conceptual in this case; the noteworthy fact, though, is that this time it is a defeasible apriority of a reason relation. If this is correct, it is no wonder that all earlier accounts of dispositions were near misses.

Such examples certainly help understanding the notion of defeasible apriority. Still, I have to admit that the dynamic conception of defeasible apriority is less clear than that of unrevisable apriority. The reference to all rational doxastic states is not so problematic. But what are initial rational doxastic states? At which point does a doxastic evolution start? One tends to genetic answers, but they are hopeless. Does it start when one learns language? But this is an unending process. Does it start at birth? But now we are led astray, just as the concept of innate ideas was misleading. Moreover, from where do rational doxastic states evolve? This does not seem to be a process in real time, since rational doxastic states usually are not actual. We have to get initiality out of its obscurity.

I have a tentative proposal: First it is clear that each doxastic state operates on a field or algebra of propositions that is a small subset of all propositions; all the other propositions are not in the grasp of the doxastic state. Now each proposition is composed of, or generated by, concepts, in analogy to how sentences are composed of subsentential expressions. Hence, for each doxastic state there is a set of concepts within its grasp, out of which the set of propositions within its grasp is formed. ${ }^{10}$

This consideration is relevant even for unrevisable apriority. I said, for instance, that a proposition is unrevisably a priori if it is believed in all possible rational doxastic states. This cannot be literally true. How can one rationally believe, say, that all bachelors are unmarried, if one has not acquired the concepts of a bachelor and a marriage? So, even here we must more cautiously say that a proposition is unrevisably a priori if and only if it is believed in all possible rational doxastic states grasping it.

Similarly for defeasible apriority. Whichever attitude to certain propositions is defeasibly a priori, this apriority can hold only for initial doxastic states that have the concepts entering into these propositions. Hence, we might say that a doxastic state is initial with respect to a given concept if and only if it contains only those attitudes to propositions formed with this concept that it must contain in order to be said to have acquired this concept. And we might continue to say that a doxastic state is initial simpliciter if and only if it is initial with respect to all concepts it has acquired.

Thereby, I have obviously deferred the issue of initiality to the question which attitudes are (unrevisably or defeasibly) a priori connected with concepts. My proposal hence looks circular. I would rather say it is incomplete. My examples above have shown what kind of propositions and attitudes may be associated with concepts. These were just examples, and I hope plausible ones. What would be needed is a complete inquiry into such a priori associations. Only then my proposal would yield a complete explanation of initiality.

I believe that this is a reasonable and promising research agenda. This may well be doubted, however. In various ways it has been objected that conceptual

${ }^{10}$ I believe all of

mental all of this should be further explicated within an individualistic or internalistic perspective on see Haas-Stent, where propositions are narrow contents and concepts their subsentential correlatcs; see Haas-Spohn, Spohn (2001) and Spohn (forthcoming, ch. 15). 
and factual information are not so clearly separable as required by this research agenda. The chief witness of this objection is Quine, of course; so many times he has argued that language and theory form an inseparable unity, thus thwarting any hope for an account of analyticity. I feel the force of this objection, and I certainly cannot dispel it here. However, I also think that the coordinates of the discussion have shifted. The conceptual and the factual is not the same as the analytic and the synthetic. Rather, we have seen that the conceptual is closely connected to, but not identical with, both the unrevisable and the defeasible a priori. Thus, the case is not predecided by this objection, even if it was correct within the old coordinates; rather, it must be radically thought through anew. My belief in the research agenda may well turn out justified then.

\section{Summary}

My intention in this paper was to show that the notion of a priori justification must be understood in quite a different than the familiar way. The familiar way, following Burge and Kitcher, tries to utilize this notion for clarifying apriority in general. Instead, I proposed that both notions, apriority and justification, are to be explained within a dynamic perspective and that this perspective at the same time accounts for their connection. Thereby, and on the basis of the distinction between unrevisable and defeasible apriority, this connection showed quite different, partially unexpected facets full of promising perspectives. My ultimate intention thus was to promote further research on these perspectives.

\section{REFERENCES}

Audi, Robert (2003), Epistemology. A Contemporary Introduction to the Iheory of Knoweledge, New York: Routledge, 2nd ed.

BonJour, Laurence (1985), The Structure of Empirical Knowledge, Cambridge, Mass.: Harvard University Press.

Burge, Tyler (2001), »Frege on Apriority «, in: Newen et al. (2001), pp. 53-87.

Carnap, Rudolf (1950), The Logical Foundalions of Probability, Chicago: Chicago University Press, 2nd ed. 1962.

Carnap, Rudolf (1956), "The Methodological Character of Theoretical Concepts«, in: H. Feigl, M. Scriven (eds.), Minnesota Studies in the Philosophy of Science, Band I, Minneapolis: University of Minnesota Press, pp. 38-76.

Coady, C. A. J. (1992), Testimony. A Philosopical Study, Oxford: Clarendon Press.

Dubois, Didier, Henri Prade (1988), Possibility Theory: An Approach to Computerized Processing of Uncertainty, New York: Plenum Press.

Ernst, Gerhard (2007), Einfübrung in die Erkenntnistheorie, Darmstadt: Wissenschaftliche Buchgesellschaft.
Field, Hartry (1996), „The A Prioricity of Logic«, Proceedings of the Aristotelian Society 96, pp. 359-379.

Gärdenfors, Peter (1988), Knoweledge in Flux. Modeling the Dynamics of Epistemic Slates, Cambridge, Mass.: MIT Press.

Goodman, Nelson (1955), Fact, Fiction and Forecast, 4th ed. Cambridge, Mass.: Harvard University Press1983, German translation: Tatsache, Fiktion, Voraussage, Frankfurt a.M.: Suhrkamp 1988.

Haas, Gordian (2005), Revision und Rechtfertigung. Eine Theorie der Theorieänderung, Heidelberg: Synchron.

Haas-Spohn, Ulrike, and Wolfyang Spohn (2001), "Concepts Are Beliefs About Essences", in: Newen et al. (2001), pp. 287-316; also in: Spohn (forthcoming), ch. 14.

Halpern, Joseph Y. (2003), Reasoning about Uncertainty, Cambridge, Mass.: MIT Press.

Huber, Franz, Christoph Schmidt-Petri (eds.) (forthcoming), Degrees of Belief. An Antbology, Oxford: Oxford University Press.

Hunter, Daniel (1990), "Parallel Belief Revision«, in: R. D. Shachter, T. S. Levitt, J. Lemmer, L. N. Kanal (eds.), Uncertainty in Artificial Intelligence 4, Amsterdam: Elsevier, pp. 241251.

Jeffrey, Richard C. (1965), The Logic of Decision, Chicago: University of Chicago Press, 2nd ed. 1983; German translation.: Logik der Entscheidungen, München: Oldenbourg 1967.

Kitcher, Philip (1980), »A Priori Knowledge«, The Philosophical Review 89, pp. 3-23.

Kitcher, Phlip (2000), »A Priori Knowledge Revisited«, in: P. Boghossian, C. Peacocke (eds.), New Essays on the A Priori, Oxford: Clarendon Press, pp. 65-91.

Kripke, Saul A. (1972), »Naming and Necessity« in: D. Davidson, G. Harman (eds.), Semantics of Natual Language, Dordrecht: Reidel, pp. 253-355 + 763-769; ext. ed.: Oxford: Blackwell 1980; German translation: Name und Notwendigkeit, Frankfurt a.M.: Suhrkamp 1981.

Newen, Albert, Ulrich Nortmann, and Rainer Stuhlmann-Laeisz (eds.) (2001), Building on Frege. Nerw Essays on Sense, Content, and Concept, Stanford: CSLI Publications.

Pollock, John L. (1995), Cognitive Carpentry: A Blueprint for How to Build a Person, Cambridge, Mass.: MIT Press.

Quine, Willard V. O. (1951), "Two Dogmas of Empiricism", Philosophical Review 60, pp. 20-43.

Quine, Willard V. O. (1969), "Epistemology Naturalized «, in: W. V. O. Quine, Ontological Relativity and Other Essays, New York: Columbia University Press, pp. 69-90.

Salmon, Wesley C. (1975), »Confirmation and Relevance«, in: G. Maxwell, R.M. Anderson (eds.), Minnesota Studies in the Pbilosophy of Science, vol. VI, Minneapolis: University of Minnesota Press, pp. 3-36.

Schlick, Moritz (1934), »Über das Fundament der Erkenntnis«, Erkenntnis 4, pp. 79-99.

Scholz, Oliver R. (1999), Verstehen und Rationalität. Untersucbungen zu den Grundlagen von Hermeneutik und Sprachphilosophie, Frankfurt a.M.: Klostermann.

Spohn, Wolfgang (1983), Eine Theoric der Kausalität, unpublished Habilitationsschrift, Universität München, pdf-version at:

http://www.uni-konstanz.de/FuF/Philo/Philosophie/philosophie/files/habilitation.pdf 
Spohn, Wolfgang (1988), Ordinal Conditional Functions. A Dynamic Theory of Epistemic States", in: W.L. Harper, B. Skyrms (eds.), Causation in Decision, Belief Change, and Statistics, vol. II, Dordrecht: Kluwer, pp. 105-134; also in: Spohn (forthcoming), ch. 1. Spohn, Wolfgang (1997), "Begründungen a priori - oder: ein frischer Blick auf Dispositionsprädikate", in W. Lenzen (ed.), Das weite Spektrum der Analytischen Pbilosophie. Festscbrift für Franz von Kutschera, Berlin: de Gruyter, pp. 323-345; engl. translation in: Spohn (forthcoming), ch. 12.

Spohn, Wolfgang (1997/98), "How to Understand the Foundations of Empirical Belief in a Coherentist Way", Proceedings of the Aristotelian Society, New Series 98, 23-40; also in: Spohn (forthcoming), ch. 11.

Spohn, Wolfgang (2000), „Über die Struktur theoretischer Gründe«, in: J. Mittelstraß (ed.), Die Zukunft des Wissens. Akten des 18. Deutschen Kongresses für Philosophie, Berlin: Akademie Verlag, pp. 163-176.

Spohn, Wolfgang (2001), »Vier Begründungsbegriffe«, in: T. Grundmann (ed.), Erkenntnistheorie. Positionen zwischen Tradition und Gegenwart, Mentis, Paderborn, pp. 33-52. Spohn, Wolfgang (2005), »Anmerkungen zum Begriff des Bewusstseins«, in: G. Wolters, M. Carrier (eds.), Homo Sapiens und Homo Faber. Festschrift für Jürgen Mittelstraß, Berlin: de Gruyter, pp. 239-251.

Spohn, Wolfgang (forthcoming), Causation, Coherence, and Concepts. A Collection of Essays, Dordrecht: Springer.

Watkins, John W. N. (1957/58), »Farewell to the Paradigm-Case Argument «, Analysis 18, pp. 25-33. 